\title{
FEDERALISMO E POLÍTICAS EDUCACIONAIS NO BRASIL: EQUALIZAÇÃO E ATUAÇÃO DO EMPRESARIADO COMO PROJETOS EM DISPUTA PARA A REGULAMENTAÇÃO DO REGIME DE COLABORAÇÃO
}

\author{
Gilda CARdoso Araujo*
}

\begin{abstract}
RESUMO: O artigo analisa as relações intergovernamentais, o conceito de equalização (próprio ao federalismo de matriz cooperativa) e suas relações com o regime de colaboração, bem como os contornos recentes que as ações e proposições sobre o regime de colaboração para a educação vêm assumindo no Brasil. O percurso analítico indica que há - além da permanência do forte poder indutor da União na definição de formas de colaboração para a educação e da relação que este ente federado estabelece diretamente com os municípios, desprezando os estados - um crescente protagonismo do empresariado junto ao governo federal na tentativa de buscar outras formas de regramento do regime de colaboração, sendo a mais expressiva delas os arranjos de desenvolvimento da educação.
\end{abstract}

Palavras-chave: Federalismo no Brasil. Políticas educacionais. Relações intergovernamentais e equalização. Regime de colaboração. Arranjos de desenvolvimento da educação.

\section{FEDERALISM AND EDUCATIONAL POLICIES IN BRAZIL: \\ EQUALIZATION AND PERFORMANCE OF THE BUSINESS SECTORS AS COMPETING PROJECTS FOR THE REGULATION OF COLLABORATION}

ABSTRACT: This article examines intergovernmental relations, the concept of equalization (peculiar to a federalism of a cooperative matrix) and its relations with collaboration regulations, as well as the recent contours being shaped by the actions and propositions for collaborative partnerships regarding education in Brazil. The analytical path indicates that there is - besides the permanence of the strong inductor power of the federal government in defining the forms of collaboration for education and the relationship that this federal entity directly establishes with the municipalities, disregarding the states - significant growth in the role of the private sector, along with

Programa de Pós-Graduação em Educação da Universidade Federal do Espírito Santo (Ufes). Vitória (ES) - Brasil.

Contato com a autora:<gilda.vix@terra.com.br> 
the federal government, in attempting to seek other forms of regulations for collaboration, being the arrangements for the development of education the most expressive one.

Key words: Federalism in Brazil. Educational policies. Intergovernmental relations and equalization. Collaborative partnerships. Arrangements for the development of education.

LE FEDERALISME ET LES POLITIQUES EDUCATIVES AU BRÉSIL:

L'ÉGALISATION ET LA PERFORMANCE DE LA COMMUNAUTE DES

AFFAIRES DANS DES PROJETS CONCURRENTS POUR LA REGLEMENTATION D' UN PROGRAMME DE COLLABORATION

RÉSUMÉ: Cet article examine les relations intergouvernementales, le concept de l'égalisation (propre au fédéralisme d'origine coopérative) et leurs relations avec un programme de collaboration ainsi que les récents contours issus des actions et des propositions sur le régime de collaboration pour l'éducation au Brésil. Le parcours d'analyse indique qu'il y a - en plus de la permanence du fort pouvoir inductif de l'Union dans la définition de formes de collaboration pour l'éducation et la relation que cette entité fédérée établit directement avec les municipalités, en méprisant l'Etat - un rôle croissant de la communauté des affaires avec le gouvernement fédéral dans une tentative de chercher d'autres formes d'organisation du programme de coopération, étant la plus importante d'entre elles, les modalités de développement de l'éducation.

Mots-clés: Le fédéralisme au Brésil. Les politiques éducatives. Relations intergouvernementales et de l'égalisation. Programme de collaboration. Modalités du développement de l'éducation.

\section{Introdução}

$\mathrm{O}$

regime de colaboração é um instituto jurídico e político que regulamenta a gestão associada dos serviços públicos, sendo afeto às competências materiais comuns previstas no art. 23 da Constituição Federal de 1988. As competências materiais comuns podem ser definidas como aqueles serviços públicos que devem ser prestados por todos os entes federados, sem preponderância e de forma cumulativa, para garantir a equalização das condições de vida em todo o território de um Estado organizado em bases federativas. Neste sentido, o regime de colaboração é um dos mecanismos da matriz cooperativa ou intraestatal do federalismo.

Este artigo tem por objetivos realizar uma discussão conceitual e histórica sobre as relações intergovernamentais, o conceito de equalização (afeto ao federalismo de matriz cooperativa) e suas relações com o regime de colaboração, bem como, a partir dessa discussão, analisar os contornos recentes que as ações e proposições sobre o regime de colaboração vêm assumindo no Brasil.

O percurso analítico indica que há - além da permanência do forte poder indutor da União na definição de formas de colaboração para a educação e da relação 
que este ente federado estabelece diretamente com os municípios, desprezando os estados - um crescente protagonismo do empresariado junto ao governo federal, na tentativa de buscar outras formas de regramento do regime de colaboração que se sobrepõem às outras instâncias governamentais, federativas e também ao movimento dos educadores (como a Conae 2014), ao mesmo tempo em que passam longe da lei complementar, conforme preconizado pelo texto constitucional.

Sendo assim, os arranjos de desenvolvimento da educação como sinônimos de regime de colaboração vêm ganhando, de forma sinuosa e silenciosa, espaços cada vez mais institucionalizados, ao passo que o debate sobre a necessidade de regulamentação por lei complementar é completamente esvaziado em seu conteúdo político, substituído pela lógica econômica e neodesenvolvimentista dos arranjos produtivos locais, do reforço ao protagonismo local e do associativismo voluntário intermunicipal.

\section{Federação, federalismos e o desafio da equalização no modelo coo- perativo}

A distinção entre federação e federalismos é importante, pois existem Estados organizados constitucionalmente como federações, mas o funcionamento engendrado pelos seus arranjos federativos varia consideravelmente no tempo e no espaço, tornando os princípios políticos, jurídicos, institucionais e fiscais da federação flexíveis e dinâmicos (COSTA, 2010).

Dessa forma, é possível identificar um grande erro conceitual quando se discute o "federalismo" como a associação imediata à descentralização ou à democratização. Na verdade são as formas das relações intergovernamentais entre as unidades subnacionais e o governo central numa federação que irão tipificar o modo de atuação do Estado nacional quanto à definição de políticas públicas, segundo um perfil centralizador, não centralizador ou descentralizador (ALMEIDA, 1995).

Para analisar quaisquer dinâmicas federativas é preciso adentrar o campo das relações intergovernamentais. Em termos ideais, há dois tipos de relação intergovernamental: a competitiva e a cooperativa, que correspondem respectivamente ao modelo dual, ou federalismo interestatal (com ênfase na separação entre os níveis de governo), e ao modelo cooperativo, ou federalismo intraestatal (com ênfase no entrelaçamento entre os níveis de governo). O modelo cooperativo tem sido proposto de forma mais acabada na Alemanha. ${ }^{1}$

O pressuposto fundamental do modelo dual é a defesa da competição política, territorial e fiscal como forma de controle mútuo entre os níveis de governo, bem como a possibilidade de os cidadãos exercerem a accountability sobre as competências 
administrativas de cada nível de governo. Já o pressuposto básico do modelo cooperativo é o estímulo a uma maior integração entre as políticas, com ênfase na equalização de condições de vida em todo o território nacional.

Equalização traz etimologicamente o prefixo equi, do latim aequ(i)-, de aequusa-um, significando "igual, plano, liso, justo", derivado do latim "equidade". No que se refere aos estudos sobre federalismo, tratar da questão da equalização significa discutir duas questões relevantes: o (des)equilíbrio vertical (distribuição de encargos, competências e recursos entre governo central e governos subnacionais) e o (des)equilíbrio horizontal (diferenças entre governos subnacionais na capacidade de prestação de serviços públicos) (PRADO, 2006).

Tanto o (des)equilíbrio vertical quanto o (des)equilíbrio horizontal têm estreita relação com o grau de centralização/descentralização de três importantes dimensões: a) gasto-execução das políticas públicas de cada esfera de governo, b) bases próprias de arrecadação de cada esfera de governo e c) montante e forma das transferências intergovernamentais necessárias à execução das políticas públicas (transferências entre esferas de governo) (REZENDE, 2006).

Essa terceira dimensão é o problema básico da equalização, ou seja, como garantir para cada cidadão da Federação um padrão mínimo de serviços públicos. A importância atribuída à questão da equalização se apresenta de forma muito diferenciada nas federações existentes. Essa questão não é um valor básico, por exemplo, para os Estados Unidos (modelo dual ou federalismo interestatal). Entretanto, em outras federações, segundo os estudos comparativos de Prado (2006), como na Alemanha, na Índia, no Canadá e na Austrália, a questão da equidade tem relevo, em que pese às distintas formas de sua engenharia técnica, política e institucional.

Para isso é imprescindível o papel e a atuação do governo central, pela simples razão de que as diferenças entre capacidades econômicas e fiscais - que determinam diferentes tipos de serviços públicos - não podem ser resolvidas pelos governos subnacionais, dadas as disparidades em termos de arrecadação e em termos de provisão de bens e serviços públicos. Daí a necessidade de certa ação normativa e redistributiva do governo central. A viabilidade dessa ação do governo central depende, naturalmente, da correlação de forças que se estabelece entre os entes federados, que podem aceitar ou não a normatização, bem como as fórmulas de redistribuição das receitas (AFFONSO, 1995).

A ação do governo central e a correlação de forças entre as unidades subnacionais entre si e com a União devem convergir tanto no sentido da coordenação quanto no sentido da colaboração federativa ${ }^{2}$ para a garantia da equalização num Estado federativo de bases cooperativas. Num Estado federativo com essas bases, um dos institutos jurídicos e políticos que asseguram a equalização é o regime de 
colaboração, que teve sua origem na Alemanha, sendo prescrito também na Carta Constitucional brasileira de 1988. É essa origem e a forma de entrelaçamento entre as unidades subnacionais que passaremos a discutir na próxima seção, a fim de compreendermos o modelo de equalização alemão.

\section{A origem: o regime de colaboração na Alemanha}

O regime de colaboração na Alemanha tem seu marco inicial na época Bismark (1880), consolidando-se após a Segunda Guerra Mundial. Nesse contexto, a ordem federativa alemã ressurgiu por meio de um exaustivo processo de negociação envolvendo os Aliados e a Alemanha. Esse processo de negociação teve seu ápice no ano de 1949, com o debate sobre unitarização e federalização, centralização e descentralização que se desenvolvia desde 1945. Entre essas polarizações, foi possível, de imediato, um consenso entre os Aliados: o de que a Alemanha deveria se constituir de forma federativa e descentralizada, a fim de evitar abusos de poder, como em 1933 (MORAES, 2001).

Em 1949 foi instalada uma Assembleia Nacional Constituinte formada pelos representantes dos estados da parte ocidental. A nova constituição deveria ser aprovada pelas três nações aliadas e passar por referendo popular na Alemanha. As três nações aliadas defendiam um modelo federativo similar ao dos EUA, já os representantes alemães defendiam um modelo mais de acordo com a tradição alemã, com a primazia da União e representação dos governos nacionais na formulação das políticas públicas, via Conselho Federal, como nas experiências do II Reich e da República de Weimar.

A solução foi um modelo híbrido com as seguintes características: a) a Alemanha receberia a denominação de República Federal da Alemanha. Seria um Estado federal; b) os governos subnacionais teriam maior autonomia de competências; c) com uma maior autonomia, haveria pouca transferência de recursos; d) a forma de interação dos estados com a formulação de políticas públicas federais corresponderia a um Conselho Federal, com a participação efetiva dos estados (unidades subnacionais) (MORAES, 2001).

Porém, com o passar do tempo, o que se observou foi um entrelaçamento cada vez maior entre os entes federados da Alemanha, com o governo federal ocupando um papel cada vez mais central na consolidação de mecanismos de interdependência entre as unidades subnacionais, o que veio a se consolidar como as bases do federalismo cooperativo (SCHMITZ, 2013).

Assim, a questão da equalização esteve presente no texto constitucional de 1949 e é marca distintiva do federalismo alemão. O artigo 106, nos seus parágrafos $3^{\text { }}$ 
e $4^{\circ}$, traz instrumentos de compensação financeira vertical e horizontal. No parágrafo $3^{0}$ está definido que a União deve transferir recursos para os estados, a fim de que estes complementem gastos com educação, saúde e bem-estar social. O parágrafo $4^{\circ}$ confere à União a prerrogativa de criação de esquema de transferência de estados mais ricos para estados mais pobres, ou seja, com menor capacidade fiscal. Esses instrumentos de compensação têm por objetivo garantir a preservação de condições de vida homogêneas em todo o território alemão, o que foi assegurado, como princípio constitucional, pela reforma de 1969 da Lei Fundamental e por todas as reformas constitucionais subsequentes, como a mais recente de 2006 (FREITAG; SCHLICHT, 2009; ALEMANHA, 2011).

Percebemos que na Alemanha, ao contrário do Brasil, há uma interdependência entre os estados com o governo federal, tanto na elaboração quanto na execução das políticas sociais. Essa interdependência é assegurada por mecanismos como o Conselho Federal (Bundesrat), que corresponde a uma segunda câmara legislativa federal (a primeira é o Parlamento), composta apenas por representantes diretamente indicados pelos governadores dos estados, e mais especificamente, no caso da educação, à Comissão União-Estados para o Planejamento Educacional e a Promoção da Pesquisa (Bund-Lander Komissionfuer Bildungplanungund Forschungfoerderung), cuja regulamentação quanto à sua atuação é dada por lei federal, com a aprovação do Conselho Federal (FREITAG; SCHLICHT, 2009; ALEMANHA, 2011).

Além disso, existe o Conselho de Planejamento Financeiro (Finanzplanungsrat) e o Conselho de Conjuntura para o Poder Público (Konjunkturratuer die oeffentliche Hand), que permitem negociações mais abrangentes, além da esfera legislativa, mediando as relações entre planos de governo e gastos públicos.

Desse modo, na Alemanha, o regime de colaboração é tanto um instituto jurídico, no plano das instituições formais e definidas constitucionalmente, quanto amparado por arcabouço infraconstitucional (legislações), o que garante estabilidade quanto ao princípio da equalização das condições de vida em todo o território nacional.

No Brasil a necessidade do regime de colaboração foi prevista em vários dispositivos de nossa Carta Magna, como nos incisos II e III do art. $3^{\circ}$, no inc. VII do art. 170, no parágrafo $1^{\circ}$ do art. 174 e, mais especificamente para a educação, no inc. V e parágrafo único do art. 23. Do ponto de vista da competência legislativa, à União coube privativamente legislar sobre as diretrizes e bases da educação nacional (art. 22, inc. XXIV). Acreditava-se que, com esses dispositivos, fosse possível constituir um sistema nacional de educação, bandeira histórica dos educadores desde a década de 1930, pelo menos. Ocorre que, na área de educação, o regime de colaboração não 
foi regulamentado e, adicionalmente, evitou-se utilizar na legislação infraconstitucional (LDB) a expressão "sistema nacional de educação", substituída pela expressão "organização da educação nacional” (SAVIANI, 1997).

É exatamente nesse vácuo de indefinição quanto ao regime de colaboração e quanto ao sistema nacional de educação que várias proposições e ações vêm se materializando, muitas vezes de forma sobreposta e desarticulada, gerando um campo de disputas embaçado e movediço no âmbito do grupo dos "reformadores empresariais da educação", do governo federal (MEC), do Conselho Nacional de Educação, do Legislativo e do Fórum Nacional de Educação.

\section{Federalismo, políticas educacionais e regime de colaboração no Brasil: equalização versus associativismo de bases empresariais}

A CF de 1988 tentou conciliar um dos padrões de organização federativa mais descentralizados das 26 federações existentes no mundo ${ }^{3}$ com a ideia de uma organização nacional de ensino equânime, mediante a previsão do regime de colaboração entre os entes federados, a ser regulamentado por lei complementar. Além disso, formalizou uma notória especificidade em relação a outras federações do mundo: a inclusão do município como um terceiro ente federado.

Entretanto, a CF de 1988 potencializou os desequilíbrios federativos, pois não previu a adequada fonte de recursos para o provimento de serviços públicos descentralizados, ao mesmo tempo em que ampliou as responsabilidades das unidades subnacionais, particularmente dos municípios, com os direitos sociais. Assim, a CF de 1988 iniciou um processo de políticas descentralizadas num país extremamente heterogêneo.

A falta de regulamentação do regime de colaboração no Brasil não ocorreu por falta de tentativas. Foram elaborados cinco projetos de lei que abordavam o regime de colaboração na educação, de 1988 até o ano de 2010, todos de iniciativa do Legislativo. Entretanto não houve debate sobre a matéria, uma vez que foram arquivados sem relatoria, por fim de legislatura ou por trâmite indevido (CASSINI, 2010).

Entre as dificuldades para a falta de regulamentação do regime de colaboração para a educação está a necessidade de uma reforma fiscal que redistribua os recursos segundo as responsabilidades e as demandas de atendimento de cada ente federado, pois o que temos hoje é que, na repartição do "bolo tributário", os municípios são os que menos arrecadam e os que mais têm responsabilidade com a oferta educacional. Também há a necessidade de repactuar o federalismo brasileiro com a revisão dos mecanismos de "atuação prioritária" para a oferta das três etapas da Educação Básica inscritos na CF de 1988 (parágrafos 2º e 3ํำ do art. 211, com redação 
dada pela Emenda Constitucional n. 14/1996), que reforçam a falta de colaboração entre estados e municípios, e, ainda, de definir com clareza o que seria a "função supletiva da União" para a oferta dessa etapa de escolarização. Todas essas necessidades envolvem uma complexa tarefa de reengenharia institucional, fiscal e política, incidindo sobre o modelo federativo vigente.

Como essa complexa tarefa de reengenharia não foi levada a termo pelo Legislativo, passamos às ações e proposições do Executivo, desde 2007, com o anúncio do Plano de Desenvolvimento da Educação (PDE), que teve forte influência do movimento "Todos pela Educação" (TPE), representando os setores ligados aos "reformadores empresariais da educação" (FREITAS, 2012). Essas ações e proposições do Executivo estão muito distantes dos princípios de equalização e não incidem sobre o problema da falta de regulamentação do regime de colaboração, em conformidade com o disposto no parágrafo único do art. 23 da CF de 1988.

Atualmente, no Brasil, a bandeira da regulamentação do regime de colaboração para a educação tem sido erguida pelo poder central (governo federal) e com fortes indícios de indistinção entre coordenação federativa e colaboração. Mas esse cenário não é recente, remontando ao Governo FHC, que tomou algumas medidas no sentido de redefinir "pelo alto" o pacto federativo brasileiro para a educação.

Exemplo mais significativo dessas medidas foi a política de criação de fundos, via a Emenda Constitucional n. 14, de 1996, que criou o Fundef (depois transformado em Fundeb). O Fundef tentou, a um só tempo, resolver o problema da assimetria dentro dos municípios de um mesmo estado e normatizar, ainda que de forma precária, formas de colaboração. ${ }^{4}$ Porém a política de fundos não incide sobre as desigualdades entre os estados e as regiões brasileiras e, dessa forma, não pode ser considerada um mecanismo de equalização para a oferta educacional em todo o território nacional, portanto ainda não se traduz em regime de colaboração, embora o seja em germe, dada a sua natureza compulsória para os entes federados.

Posteriormente, o art. 241 da Constituição foi modificado a fim de aperfeiçoar os mecanismos de articulação intermunicipal, de gestão intergovernamental e propor mecanismos que permitissem o desenvolvimento de instrumento jurídico de cooperação entre os diferentes níveis de governo. Assim, a Emenda Constitucional n. 19, de 1998, determinou que a União, os estados, o Distrito Federal e os municípios disciplinassem, por meio de lei, os consórcios públicos e os convênios de cooperação entre os entes federados, autorizando a gestão associada de serviços públicos, bem como a transferência total ou parcial de encargos, serviços, pessoal e bens essenciais à continuidade dos serviços transferidos. ${ }^{5}$

Esse dispositivo constitucional teve impacto inexpressivo para a área de educação, pois, embora o consórcio público seja uma das formas mais conhecidas de 
cooperação entre entes federados, ${ }^{6}$ especialmente entre municípios, a sua principal característica é se constituir como uma cooperação acordada, o que não é uma característica da Federação brasileira, com perfil marcadamente predatório e hierárquico.

Ademais, além das muitas exigências burocráticas e dificuldades operacionais para a constituição dos consórcios públicos, suas principais vantagens consistem nos ganhos de escala de produção ou de aquisição, racionalização dos recursos financeiros e padronização de suprimentos, vantagens essas que não estão vinculadas à prestação direta dos serviços públicos de educação (excetuando transporte e merenda escolar). Talvez por isso a inexistência de consórcios monotemáticos de educação, contrastando com sua expressiva disseminação na área da saúde. Por essas razões os consórcios públicos também tiveram impacto inexpressivo para a configuração de formas de colaboração para a prestação de serviços educacionais e, fundamentalmente, para o avanço quanto à proposição de mecanismos eficazes de equalização da oferta educacional.

Outras ações de coordenação da União, com a indução de políticas para a área de educação, foram traduzidas como colaboração, como é o caso dos testes em larga escala e das definições curriculares. Recentemente tivemos o Plano de Desenvolvimento da Educação (PDE) e o Plano de Ações Articuladas (PAR), que serviram de base para os novos contornos que as ações e proposições sobre a definiç̧ão do regime de colaboração vêm assumindo no cenário atual.

Esses novos contornos, acerca do regime de colaboração para a educação, têm forte matriz empresarial, com um arcabouço teórico que valoriza conceitos de territorialidade, associativismo intermunicipal voluntário, redes, protagonismo local e visão estratégica, a partir de metas e resultados, estando assentados nos chamados arranjos produtivos locais, adaptados para a educação sob a forma de arranjos de desenvolvimento da educação (ADE), regulamentados pela Resolução n. 1/2012 do Conselho Nacional de Educação.

Os ADE remontam ao contexto de elaboração do PDE e do PAR como instrumento de diagnóstico nos municípios brasileiros, em 2007, e ao protagonismo que o empresariado paulista assumiu nessa empreitada via o movimento "Todos pela Educação" (TPE), criado em setembro de 2006 (ARAUJO, 2012).

Desde o ano de 2009 os ADE passaram a funcionar em diferentes lugares do país com o envolvimento do TPE, do MEC, de Secretarias de Educação, de universidades, de Conselhos de Educação e de institutos e fundações ligados a empresas, como Instituto Votorantim, Fundação Vale, Consórcio Estreito Energia, Instituto Natura, Comunidade Educativa Cedac, Instituto MindGroup, Instituto Gerdau, Fundação Itaú Social, entre outros (ABRUCIO; RAMOS, 2012). 
A proposta dos ADE teve enormes vitórias quanto à sua institucionalização no ano de 2010, pois uma comissão ${ }^{7}$ foi composta no âmbito da Câmara de Educação Básica (CEB), do Conselho Nacional de Educação (CNE), ${ }^{8}$ com a finalidade de analisar proposta de fortalecimento e implementação do regime de colaboração mediante os ADE.

Em 30 de agosto de 2011 a comissão constituída no âmbito da CEB do CNE apresentou o Parecer n. 9, que foi aprovado. Com uma introdução que articula a qualidade social, a construção de um sistema nacional de educação e a necessidade de "[...] colocar em prática o regime de colaboração [...]" (BRASIL, 2011, p. 2; grifos nossos), o documento propugna que os municípios colaborem de forma horizontal, mediante os ADE, na mesma perspectiva do movimento TPE: trabalho em rede em que municípios com proximidade geográfica (territorialidade) e características sociais e econômicas semelhantes busquem trocar experiências e solucionar problemas na área de educação, em articulação com o estado e com a União (BRASIL, 2011). Posteriormente, em 23 de janeiro de 2012, o MEC homologou o parecer com sua respectiva proposta de resolução (Resolução n. 1/2012).

No mesmo ano em que fora aprovado o parecer dos ADE pelo CNE, ou seja, ainda em 2011, foi constituída, no âmbito do MEC, a Secretaria de Articulação com os Sistemas de Ensino (Sase), criada pelo Decreto n. 7.480, de 16 de maio de 2011, que tem como uma de suas atribuições apoiar o desenvolvimento de ações para a criação de um sistema nacional de educação, aprofundando o regime de colaboração entre os entes federados.

É curioso observar que, no âmbito do TPE (empresariado), do CNE e do MEC, há um discurso uníssono quanto a "colocar em prática" ou "aprofundar" o regime de colaboração, sendo que, como vimos, não há regulamentação deste por lei complementar, conforme preconizado pela CF de 1988.

Outro dado digno de nota é que, no âmbito do governo federal, já existia uma instância de proposições para a coordenação e cooperação entre os entes federados: o Comitê de Articulação Federativa (CAF). Embora criado em 2003, apenas no ano de 2007 o CAF foi instituído formalmente como instância de diálogo entre a União e os municípios brasileiros, sob a chancela da Secretaria de Relações Institucionais da Presidência da República. Sua composição prevê, além da participação do ministro de Estado das Relações Institucionais, que preside o comitê, a participação de 18 ministérios cujas políticas têm maior impacto no âmbito municipal e de 18 integrantes das entidades nacionais de representação de municípios: Associação Brasileira de Municípios $(\mathrm{ABM})$, Frente Nacional de Prefeitos (FNP) e Confederação Nacional de Municípios (CNM). Dessa forma, o CAF desconsidera a instância estadual como ente federativo, definindo as relações governamentais apenas entre o governo federal e os municípios, 
o que tem sido a tônica da relação que o governo federal vem estabelecendo no âmbito da Federação brasileira, a exemplo dos ADE $^{9}$ (PORTAL FEDERATIVO, 2012).

Os ADE vêm ganhando tanta adesão no campo empresarial e governista (Executivo e Legislativo) que foram incluídos no Projeto de Lei da Câmara n. 103/2012, que trata do Plano Nacional de Educação (PNE) (BRASIL, 2012a) como forma de "fortalecimento do regime de colaboração entre os municípios" (parágrafo 6⿳0 do art. $7^{\circ}$ ), desconsiderando várias emendas dos movimentos de educadores, inclusive as do Centro de Estudos Educação e Sociedade (Cedes).${ }^{10}$ Além de incluído no projeto de lei em tramitação relativo ao PNE, em 11 de outubro de 2012 o MEC, por meio da Portaria n. $1.238,{ }^{11}$ constituiu um grupo de trabalho para elaborar estudos sobre a implementação de regime de colaboração mediante ADE (GT-ADE).

A portaria define que o GT-ADE deverá apresentar um relatório final no prazo de 90 dias, ${ }^{12}$ contados da data da publicação do ato de designação de seus membros, e que esse relatório deverá: a) elencar as experiências mais importantes de ADE ou semelhantes no Brasil; b) caracterizar essas experiências; c) apontar os êxitos e as dificuldades dessas experiências, explicando-os; d) propor, no âmbito dos programas desenvolvidos pelo MEC, ações que possam colaborar com os ADE; e) aprofundar estudos sobre a possibilidade de os consórcios públicos se constituírem como uma forma de consolidação dos ADE; f) estudar a possibilidade de utilização dos recursos do Fundeb para projetos e programas consorciados ou nas formas de ADE; g) analisar a possibilidade de assistência técnica ou financeira por parte do FNDE ou do MEC como mecanismo de colaboração; h) elaborar diagnósticos microrregionais que demonstrem vulnerabilidade no campo educacional, indicando sugestões para o seu enfrentamento com base em ações colaborativas entre os sistemas de ensino (BRASIL, 2012b).

A perspectiva sobre o regime de colaboração, a partir de uma concepção de ação territorial, vem sendo discutida pelo TPE e pelo MEC, por meio da Sase. O TPE avalia que há a necessidade de "uma mudança de cultura, que exige não apenas tempo para se consolidar, mas também disciplina e organização permanentes" (CRUZ, 2012, p. 149), requerendo de institutos e fundações uma maior articulação, para evitar sobreposições. Dessa forma, Priscila Cruz (2012) propõe a organização das empresas, instituições e fundações em grupos com modos de atuação distintos, mas articulados, para a operacionalização dos ADE:

O processo de articulação e de cooperação poderia ser implementado mediante o aval das várias instituições apoiadoras dos Arranjos, que, a priori, poderiam ser identificadas em três grupos distintos:

Grupo 1: Todos pela Educação, Comunidade Educativa Cedac, Instituto Chapada, Instituto MindGroup e Fundação Getúlio Vargas de São Paulo, entre outras, cujo papel seria mais de mobilização, fomento de estudos, formação in loco e desenvolvimento do modelo. 
Grupo 2: Fundação Vale, Instituto Natura, Fundação Lemann, Instituto Gerdau, Instituto Votorantim, Mindlab e Fundação Itaú Social, entre outras, cujo papel seria o da corresponsabilidade social na gestão e no financiamento.

Grupo 3: instituições internacionais, como a Unesco, que poderiam contribuir como observadores externos do processo de implantação e de funcionamento dos Arranjos.

Com esse perfil multi-institucional, esse instituto ou conselho teria como missão apoiar a estruturação e o desenvolvimento de ADE visando ao fortalecimento do Regime de Colaboração entre municípios, em articulação com estados e União, e a consequente melhoria dos indicadores educacionais do território. (CRUZ, 2012, p. 150 e 151)

Note-se aqui o esforço de organização do TPE no sentido de pautar uma agenda e definir não só o papel e a atuação das empresas, instituições e fundações privadas, ou não estatais, para a chamada "operacionalização do regime de colaboração" pela via dos ADE, como também definir o papel e a atuação do Poder Público, especialmente o federal, de modo a transformar os ADE numa política de Estado que abranja todos os outros entes federativos, referendando os termos do parecer e da resolução do $\mathrm{CNE}$ que tratam dos $\mathrm{ADE}$ como sinônimo do regime de colaboração para a educação.

Além de ações e proposições no âmbito dos setores empresariais, do governo, do CNE e do Legislativo, há também a segunda edição da Conferência Nacional de Educação (CONAE 2014), convocada pelo Fórum Nacional de Educação, tendo como tema central "O PNE na articulação do Sistema Nacional de Educação: participação popular, cooperação federativa e regime de colaboração" com a finalidade de deliberar sobre um conjunto de propostas que subsidiem a implementação do PNE, a partir da indicação de mecanismos de colaboração entre os entes federados e os sistemas de ensino, reconhecendo o regime de colaboração como núcleo do SNE (CONAE, 2013).

Todavia nem o PNE está aprovado e, como vimos, o regime de colaboração e a cooperação federativa são concepções em disputa, de maneira que, se havia dificuldades para definir o regime de colaboração para a educação por questões de ordem fiscal e questões relativas à natureza da nossa Federação, hoje essa tarefa demanda um esforço ainda maior no sentido de enfrentar as concepções empresariais que se afastam do sentido de equalização do modelo cooperativo de federação inscrito na CF de 1988.

\section{Conclusão}

Das parcas tentativas de regulamentação no Legislativo até o ano de 2010, passamos para investidas do Executivo a partir da aprovação do PDE, em 2007, sob o signo dos interesses dos reformadores empresariais pelas políticas educacionais. 
Dessa maneira, ações e proposições vêm sendo levadas a termo sob a forma de ADE, contando com a adesão de governos, secretarias, conselhos de Educação, institutos e fundações empresariais, e com o protagonismo de alguns atores do TPE nos órgãos de governo, particularmente no MEC e no CNE.

Assim, as ações indutoras da União, somadas à peculiaridade das relações intergovernamentais diretas entre União e municípios (com desconsideração dos estados), ao avanço dos ADE e ao vazio político e jurídico deixado pela falta de regulamentação do regime de colaboração por lei complementar, têm tornado o debate sobre a configuração de um sistema nacional de educação (SNE) algo cada vez mais complexo, instável, movediço e nebuloso.

Isso porque a instituição do SNE passa necessariamente pela via da lei complementar do regime de colaboração, que dará materialidade e caráter de compulsoriedade às responsabilidades, corresponsabilidades, atribuições concorrentes, complementares e colaborativas entre os entes federados e os sistemas de ensino.

É exatamente esse o campo de disputa: de um lado os reformadores empresariais defendendo os ADE como sinônimo do regime de colaboração e tentando esvaziar a possibilidade política de sua regulamentação; de outro os profissionais da educação em vários órgãos e instâncias tentando compreender nosso complexo pacto federativo e buscando alternativas de financiamento e possibilidade de fóruns interfederativos que possam se institucionalizar e servir de base para a lei complementar do regime de colaboração que assegure a oferta de educação em quantidade e qualidade com base no princípio da equalização.

\section{Notas}

1. Também na Austrália e no Canadá, excetuando Quebéc.

2. É preciso que se faça uma distinção entre coordenação e colaboração federativa, pois ao passo que a primeira se constitui em procedimento que busca resultado comum a partir do governo central, apesar da autonomia dos entes federados, a colaboração federativa se traduz no modo de atribuições e exercício das competências concorrentes e comuns, devendo a tomada de decisões e o exercício das competências serem conjuntos e não isolados.

3. De 193 países, 26 adotam o federalismo, sendo que seus cidadãos representam cerca de $40 \%$ da população do mundo. São os seguintes os países federalistas: África do Sul, Alemanha, Argentina, Austrália, Áustria, Bélgica, Bósnia e Herzegovina, Brasil, Canadá, Comores, Emirados Árabes Unidos, Etiópia, Estados Unidos, Índia, Iraque, Malásia, México, Micronésia, Nepal, Nigéria, Paquistão, Rússia, São Cristóvão e Névis, Sudão, Suíça e Venezuela. Disponível em: <http://wiki.answers. com/Q/List_of_federal_countries_in_the_world>. Acesso em: 18 abr. 2013.

4. Diferenciamos regime de colaboração de formas de colaboração, no sentido de que o regime de colaboração é um instituto jurídico e administrativo que abrange os aspectos mais gerais de uma política pública. É o que objetiva o parágrafo único do art. 23 da CF/88. Formas de colaboração seriam aspectos mais pontuais da política educacional (por exemplo, as formas de colaboração entre estados e municípios no oferecimento do transporte escolar), como objetiva o art. $211, \S 4^{\circ}$, da

Educ. Soc., Campinas, v. 34, n. 124, p. 787-802, jul.-set. 2013 
$\mathrm{CF} / 88$, in verbis: "Na organização de seus sistemas de ensino, a União, os Estados, o Distrito Federal e os Municípios definirão formas de colaboração, de modo a assegurar a universalização do ensino obrigatório".

5. A Lei n. 11.107, de 6 de abril de 2005, estabelece normas gerais de contratação de consórcios públicos, regulamentando a matéria e prevendo a gestão associada de serviços públicos.

6. Os consórcios públicos não são recentes na história brasileira. Desde a Constituição de 1937 (art. 29) havia a previsão de agrupamento de municípios para a administração de serviços públicos. Há registro da existência de consórcios públicos nas décadas de 1950, 1960 e 1970. Mas foi somente a partir dos anos de 1980 que o consorciamento passou a ser uma prática mais comum, especialmente na área da saúde (ABRUCIO; SOARES, 2001).

7. Integraram essa comissão Mozart Neves Ramos, Cesar Callegari (ambos ligados ao TPE), Adeum Hilário Sauer (ex-presidente da União Nacional dos Dirigentes Municipais de Educação (Undime), ex-secretário de educação do município de Itabuna e do Estado da Bahia e assessor do MEC), José Fernandes Lima (diretor de programas da Coordenação de Aperfeiçoamento de Pessoal de Nível Superior (Capes) e secretário de Educação de Sergipe entre 2007 e 2010, na primeira gestão do governador Marcelo Déda - PT) e Rita Gomes do Nascimento (membro do Colegiado de Culturas Indígenas do Conselho Nacional de Políticas Culturais (CNPC), do Ministério da Cultura, e membro da Comissão Nacional de Educação Escolar Indígena).

8. Atualmente existem mais duas comissões paralelas no âmbito no CNE que tratam de forma direta ou indireta o regime de colaboração. Uma constituída no âmbito na Câmara de Educação Básica (CEB), com o intuito de propor planos regionais de educação com base nos progressos dos ADE, e outra, bicameral (CEB e Câmara de Educação Superior), para normatizar o regime de colaboração.

9. É importante destacar que, entre as resoluções do CAF, duas são relativas ao PDE: a) a Resolução CAF $n^{\circ} 2$, de 4 de junho de 2007, que propõe a instituição de Grupo de Trabalho Interministerial com a finalidade de elaborar proposta para o ressarcimento dos municípios que atenderem com transporte escolar os alunos das redes estaduais; b) a Resolução CAF no 3, de 6 de agosto de 2007, que institui o Grupo de Trabalho Interfederativo com a finalidade de acompanhar o desenvolvimento das ações do Plano de Desenvolvimento da Educação (PDE).

10. Ver o documento "Emendas do Cedes ao Projeto de Lei n. 8.035/2010". Disponível em: <http:// www.cedes.unicamp.br/EMENDAS\%20COMPLETA\%20-\%20CAPA\%20-\%20APRESENTACAO. pdf $>$. Acesso em: 8 maio 2013.

11. Em suas considerações a portaria ministerial elenca: a) o disposto no art. 211 , $\S 4^{\circ}$, da Constituição, com redação dada pela Emenda Constitucional n. 59, de 11 de novembro de 2009; b) a necessidade de superação da dualidade entre as redes municipais e estaduais, bem como a necessidade de superação das desigualdades entre estados e municípios brasileiros, o que exige responder a esse desafio numa perspectiva territorial, operado pelo conceito de arranjo educativo, acoplando as dimensões educacional e territorial; c) as recentes experiências de Arranjos de Desenvolvimento da Educação com base nas dimensões do Plano de Ações Articuladas (PAR); d) o teor da Resolução n. 1, de 23 de janeiro de 2012, da Câmara de Educação Básica do Conselho Nacional de Educação, que dispõe sobre a implementação do regime de colaboração mediante Arranjo de Desenvolvimento da Educação (ADE), como instrumento de gestão pública para a melhoria da qualidade social da educação.

12. A Portaria n. 189, de 13 de março de 2013, do MEC, retificou o artigo $3^{\circ}$ da Portaria n. 1.238/2012, estendendo o prazo para a apresentação do relatório final do GT-ADE. Assim, dos 90 dias contados a partir da designação de seus membros, o GT-ADE tem o prazo de 180 dias prorrogáveis por igual período para apresentar o relatório final.

\section{Referências}

ABRUCIO, F.L.; RAMOS, M.N. Apresentação. In: ABRUCIO, F.L.; RAMOS, M.N. Regime de colaboração e associativismo territorial: arranjos de desenvolvimento da educação. São Paulo: Fundação Santillana, 2012. 
ABRUCIO, F.L.; SOARES, M.M. Redes federativas no Brasil: cooperação municipal no Grande ABC. São Paulo: Fundação Konrad Adenauer, 2001. (Pesquisas, n. 24).

AFFONSO, R.B.A. A federação no Brasil: impasses e perspectivas. In: AFFONSO, R.B.A.; SILVA, P.L.B. A federação em perspectiva: ensaios selecionados. São Paulo: Fundap, 1995.

ALEMANHA. Lei Fundamental da República Federal da Alemanha. Tradutor Assis Mendonça; Revisor jurídico Urbano Carvelli. Edição impressa. Atualização: janeiro de 2011.

ALMEIDA, M.H.T. Federalismo e políticas sociais. Revista Brasileira de Ciências Sociais, São Paulo, v. 10, n. 28, p. 88-108, jun. 1995.

ARAUJO, G.C. Federalismo cooperativo e arranjos de desenvolvimento da educação: o atalho silencioso do empresariado para a definição e regulamentação do regime de colaboração. Revista Brasileira de Política e Administração da Educação, Recife, v. 28, n. 2, p. 515-531, mai./ago. 2012.

BRASIL. Ministério da Educação. Conselho Nacional de Educação. Parecer n. 9, de 30 de agosto de 2011. Análise de proposta de fortalecimento e implementação do regime de colaboração mediante arranjos de desenvolvimento da educação. Brasília, DF: MEC/CNE, 2011. Disponível em: <http://www.portal.mec.gov.br>. Acesso em: 2 mar. 2012.

BRASIL. Ministério da Educação. Portaria n. 1.238, de 11 de outubro de 2012. Constitui Grupo de Trabalho para elaborar estudos sobre a implementação de regime de colaboração mediante arranjos de desenvolvimento da educação. Brasília, DF: MEC, 2012b. Disponível em: <http://www.cmconsultoria.com.br/imagens/diretorios/diretorio14/ arquivo4238.pdf>. Acesso em: 3 mar. 2013.

BRASIL. Projeto de Lei da Câmara n. 103, de 2012 (n. 8.035/2010, na Casa de Origem). Aprova o Plano Nacional de Educação e dá outras providências. Brasília, DF: Senado Federal, 2012a. Disponível em: <http://www.senado.gov.br/atividade/materia/ getPDF.asp?t=115871\&tp=1>. Acesso em: 2 jun. 2013.

CASSINI, S.A. Federação e educação no Brasil: a atuação do Poder Legislativo nacional para a regulamentação do regime de colaboração. 2010. Dissertação (Mestrado) - Programa de Pós-Graduação em Educação, Universidade Federal do Espírito Santo, Vitória.

CONFERENCIA NACIONAL DE EDUCAÇÃO (CONAE). Documento-referência, elaborado pelo Fórum Nacional de Educação. Brasília, DF: MEC, Secretaria Executiva Adjunta, 2013.

COSTA, V.M.F. Federalismo e relações intergovernamentais: implicações para a reforma da educação no Brasil. Educação E Sociedade, Campinas, v. 31, n. 112 , p. 729-748, jul./set. 2010. 
CRUZ, P. Contribuição para o fortalecimento do regime de colaboração. In: ABRUCIO, F.L.; RAMOS, M.N. Regime de colaboração e associativismo territorial: arranjos de desenvolvimento da educação. São Paulo: Fundação Santillana, 2012. p. 143-151.

FREITAG, M.; SCHLICHT, R. Educational federalism in Germany: foundations of social inequality in education. Governance: an international journal of policy, administration, and institutions, v. 22, n. 1, p. 47-72, 2009. Disponível em: <www3.interscience.wiley. com>. Acesso em: 12 jul. 2012.

FREITAS, L.C. Os reformadores empresariais da educação: da desmoralização do magistério à destruição do sistema público de educação. Educação \& Sociedade, Campinas, v. 33, n. 119, p. 379-404, abr./jun. 2012.

MORAES, M.R. As relações intergovernamentais na República Federal da Alemanha: uma análise econômico-institucional. São Paulo: Fundação Konrad Adenauer, 2001. (Pesquisas, n. 22).

PORTAL FEDERATIVO. 2012. Disponível em: <www.portalfederativo.gov.br/bin/ view/Inicio/ComiteDeArticulacaoFederativa-CAF>. Acesso em: 30 abr. 2013.

PRADO, S. Equalização e federalismo fiscal: uma análise comparada. Rio de Janeiro: Fundação Konrad Adenauer, 2006.

REZENDE, F. Desafios do federalismo fiscal. São Paulo: FGV, 2006.

SAVIANI, D. A nova lei da educação: LDB trajetória, limites e perspectivas. Campinas: Autores Associados, 1997.

SCHMITZ, G. Development of education in Germany. 2013. Disponível em: <http:// www.oecd.org/edu/research/1818686.pdf >. Acesso em: 9 mar. 2013.

Recebido em 26 de junho de 2013.

Aprovado em 16 de julho de 2013. 